\title{
Hereditary Quivering of the Chin
}

\author{
B. M. LAURANCE, W. B. MATTHEWS ${ }^{\star}$, and J. H. DIGGLE \\ From the Derbyshire Hospital for Sick Children, the Derbyshire Royal Infirmary, \\ and the Grantham and Kesteven General Hospital
}

In 1930 Frey described an unusual involuntary movement of the muscles of the chin, inherited as a dominant characteristic through five generations. Ganner (1938) described a similar family, and in discussion Westphal (1938) mentioned a family in whom this trait could be followed through six generations. Grossman (1957) and Wadlington (1958) reported smaller affected families, and Ford (1960) mentioned that he had encountered the condition. There appears to be no description of its occurrence in Great Britain and the purpose of this paper is to record two such families and to emphasize the benign nature of what at first sight may appear an alarming symptom.

\section{Family A}

The pedigree is shown in Fig. 1. No consanguineous marriages were known.

III. 5. At the age of 5 this boy was referred to hospital because of what his mother described as a 'dithering chin'. This movement had occurred almost daily since birth. It was frequently precipitated by emotional disturbance, pleasurable or otherwise, and was not present during sleep. Often it would appear for no obvious reason. When severe, it interfered with his speech and he sometimes held his chin or bit his lower lip in an attempt to prevent it.

He had been born at home by normal delivery and his development had been normal. He had had measles, chicken-pox, and whooping cough.

Examination showed no abnormality of any kind apart from the periodic involuntary movement of the chin. This consisted of a very rapid quivering movement, apparently due to contraction of the mentalis muscle, persisting for several minutes. It occasionally spread to the muscles at the left angle of the mouth, and was usually but not invariably precipitated by the stress of examination. There was no weakness of the facial muscles and no involuntary movement elsewhere.

I. 1. The boy's paternal grandfather was seen at the

Received June 27, 1967.

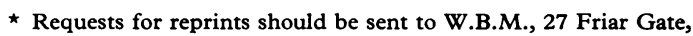
Derby. age of 66 . He was reticent about his family and gave conflicting accounts but he appears to be the youngest and sole survivor of several brothers and sisters. $\mathrm{He}$ stated that his parents and sibs had not been affected, but that he had had 'flickering of the chin' for as long as he could remember. This had gradually become less frequent so that it now occurred in attacks lasting up to 30 minutes at intervals of several years. He did not know of any precipitating factors. In the past he had sometimes had to wear a scarf to conceal the movement. No involuntary movement was observed.

II. 1. Male. Died in infancy. Thought not to be affected.

II. 2. Female. Died at the age of 24 of pneumonia and had not been affected. Her two children, III. 1 and 2 , were not seen but were stated to be unaffected.

II. 3. The father of the propositus was seen and was not affected. His wife had a son by an earlier marriage (not shown on the chart) and three unaffected daughters by her second marriage.

II. 4. Female. She was seen at the age of 36 . She had suffered from quivering of the chin for as long as she could remember but, as with her father, it had gradually decreased in frequency. She said that she would sometimes feel 'dreamy' while the movement was present. She was reluctant to discuss the condition and no abnormality was observed. Her two sons were not affected.

II. 5. Male. He was not seen but it was stated that neither he nor his three sons were affected.

II. 6. Female. She was seen at the age of 29. She was more communicative than other members of the family and said that she had had the abnormal movement all her life. It still occurred frequently, being precipitated by any fright or shock, by sexual intercourse, and by being 'kissed' by her pet budgerigar.

A fine quivering of the chin, of which she was not aware, was observed at frequent intervals during the interview and there were a few brief spasms of stronger contractions, confined to the mentalis muscle, and which she thought were provoked by the stress of examination. No other abnormality was observed.

Her two daughters were stated not to be affected. 


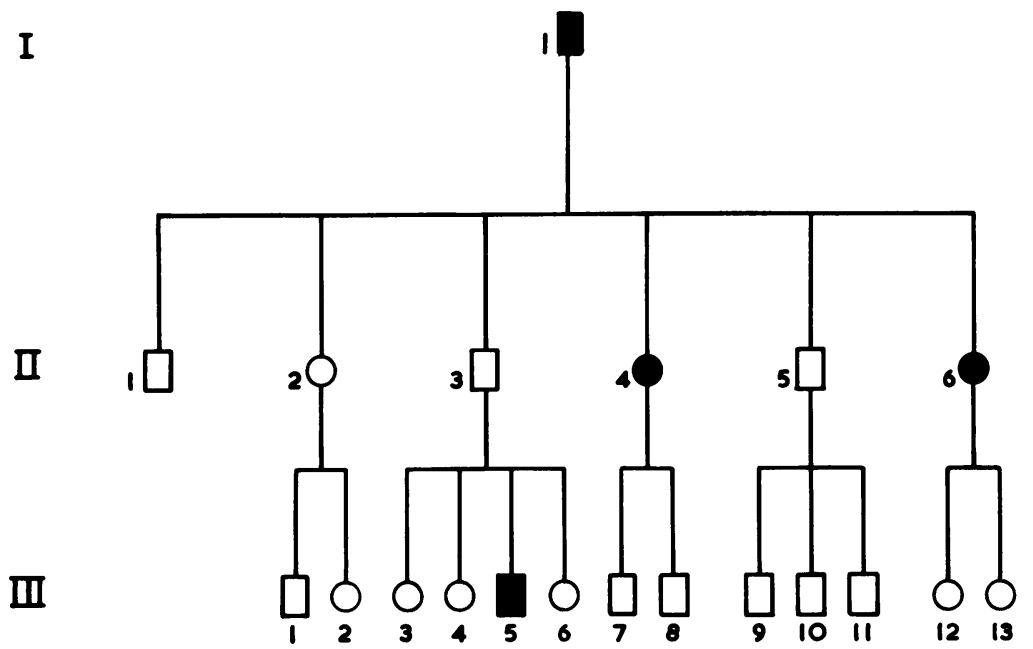

Fig. 1.-Pedigree of family A. Affected members in black.

\section{Family B}

This family (observed by J.H.D.) was not known to be related to Family A.

The propositus was a boy of 6 referred to hospital because of migraine. At the age of 1 month he had been investigated for jaundice and urinary infection and a bifid left renal pelvis was discovered. He had later been treated surgically for convergent strabismus. For two years he had suffered from periodic headache and vomiting.

On examination he still had a slight convergent squint and also coarse horizontal nystagmus.

The characteristic quivering movement of the chin was noted to be present almost continuously during his attendance at hospital. His mother stated that this had probably been present since birth but it had not been noted on his attendance at hospital in the first year of life. It occurred spontaneously and on emotional disturbance many times every day.

He had two sisters aged 23 and 16, of whom the latter had also suffered from 'chin wobbling' since birth but less severely than her brother. She could not be persuaded to attend for examination.

The child's mother also suffered from an identical condition which still occurred frequently in any situation of stress and which was observed when she brought her child to hospital. Her elder sister and two elder brothers were not known to be affected, but her father and paternal grandmother, now deceased, had also had the condition all their lives. No other examples of nystagmus were known but the patient's nystagmus had not been noticed by his mother. No further information was available about other members of the earlier generations.

\section{Investigation}

An electroencephalogram (EEG) was obtained on the propositus of family A. It contained posterior activity in the alpha range bilaterally and some rhythmic theta activity, more pronounced on the left. The chin was quivering almost throughout the recording but in the brief intervals when it was not there was no change in the record. The EEG was thought to be normal for his age.

Electromyographic (EMG) recordings with fine coaxial needle electrodes were obtained in the two members of family $A$ in whom the quivering was observed (II. 6 and III. 5). The records were very similar, showing almost rhythmic discharges of high voltage polyphasic complexes at approximately 10 a second (Fig. 2, A and B) and were thought to result from several normal motor units firing synchronously. In the boy, in whom the quivering was almost continuous at the time, it was possible to record the effect of voluntary movement. This did not affect the rhythm of the abnormal discharges which were followed by a brief silent period of up to 40 milliseconds (Fig. 2 C).

\section{Discussion}

All the published pedigrees suggest dominant inheritance with almost complete penetrance. This was not so striking in the present family $A$, the father of the propositus being unaffected though his own father had the trait. In family $B$ the abnormality could be traced through 4 generations.

In other respects the condition conforms to features noted in earlier reports; the onset at birth, the lessening severity with increasing age, and the precipitation by certain specific activities. The stimulus of being lightly pecked on the lips by a budgerigar in II. 6 is paralleled by other stimuli, specific for each patient, such as playing the violin or pouring out coffee (Frey, 1930).

In Frey's family there were two cases of congenital 


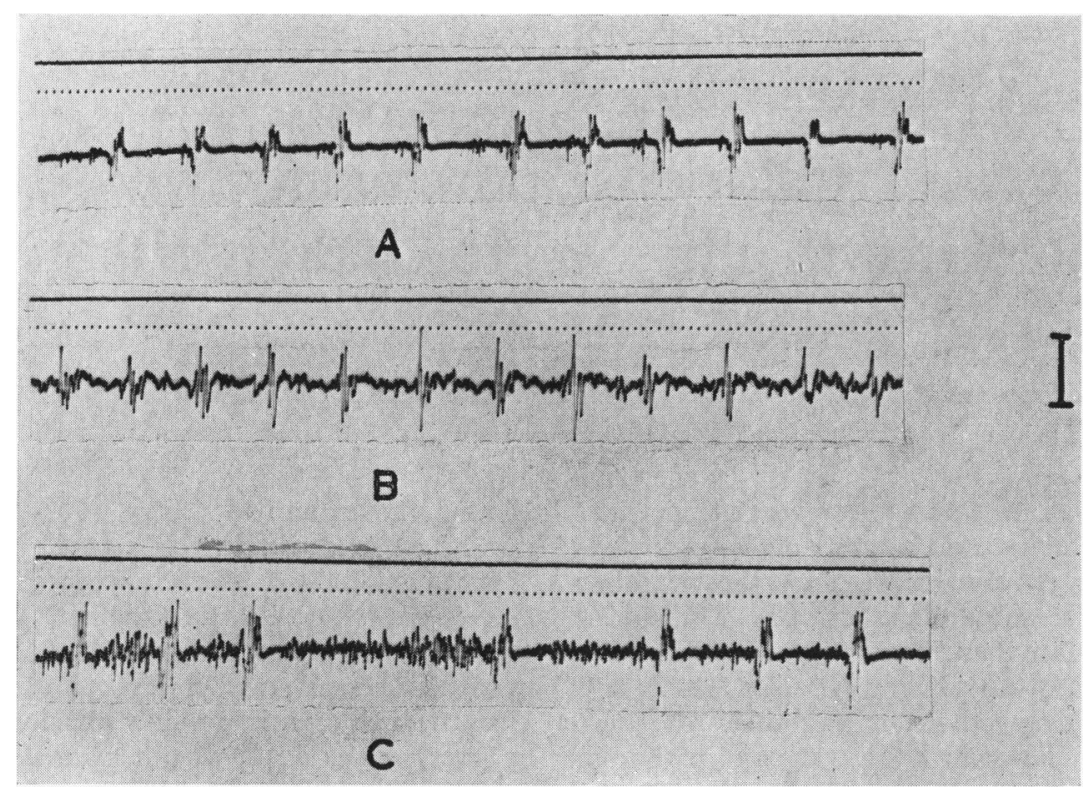

FIG. 2.-EMG recordings: $(A)$ III. 5, and $(B)$ II. 6, showing almost rhythmic discharges from the mentalis muscles.

(C) III. 5, showing the effect of quivering of the chin on voluntary activity. Calibration $1 \mathrm{mV}: 10 \mathrm{msec}$.

nystagmus, which may be relevant in view of the nystagmus present in the propositus of family $B$. In Grossman's (1957) family otosclerosis was an accompanying abnormality but was clearly inherited separately. In general, however, quivering of the chin appears as an isolated finding.

The nature of the abnormality can only be a matter of speculation. The EMG, described here for the first time, suggests that the movement is due to rapid rhythmic simultaneous discharge of a number of motor units, producing what is virtually a tetanic twitch. This has the same effect on voluntary movement as an electrically induced tetanus, being followed by a silent period. It is not accompanied by any disturbance of the EEG, though non-specific abnormalities were described by Wadlington (1958), and is unlikely to be an epileptic phenomenon. Although there are many differences, particularly in frequency, the movement more closely resembles the myoclonus occurring in brain-stem disorders. The EMG pattern is quite different from that of facial myokymia (Matthews, 1966) in which single motor units fire in short rhythmic bursts, each unit at a different frequency.

It is not possible to account for the localization to the mentalis muscle with only occasional spread to neighbouring muscles. There is no obvious connexion with the palmo-mental reflex for which some evidence of dominant inheritance exists (Abe, 1965).
Quivering of the chin is sometimes distressing and embarrassing to the patient, and may cause concern when first encountered, but is an entirely benign condition. Wadlington (1958) thought that some improvement could be obtained with phenytoin and tranquillizing drugs, but in view of the good prognosis we did not consider their long-term use justifiable in our patients.

\section{Summary}

Quivering of the chin is described in four members of one family in three generations and in five members in four generations in another. The clinical and EMG observations are described and discussed.

\section{REFERENCES}

Abe, K. (1965). Genetic aspects of the palmo-mental reflex. Acta genet. (Basel), 15, 327.

Ford, F. R. (1960). Diseases of the Nervous System in Infancy, Childhood and Adolescence, 4th ed., p. 214. Thomas, Springfield, Illinois.

Frey, E. (1930). Ein streng dominant erbliches Kinnmuskelzittern. Disch. Z. Nervenheilk., 115, 9.

Ganner, H. (1938). Erbliches Kinnzittern in einer Tiroler Talschaft. Z. ges. Neurol. Psychiat., 161, 259.

Grossman, B. J. (1957). Trembling of the chin: an inheritable dominant character. Pediatrics, 19, 453.

Matthews, W. B. (1966). Facial myokymia. F. Neurol. Neurosurg. Psychiat., 29, 35.

Wadlington, W. B. (1958). Familial trembling of the chin. $f$. Pediat., 53, 316.

Westphal (1938). Discussion (to Ganner, 1938). Z. ges. Neurol. Psychiat., 161, 265. 